\title{
Increased memory phenotypes of CD4+ and CD8+ T cells in children with sickle cell anaemia in Tanzania
}

\author{
EMMANUEL BALANDYA ${ }^{1 *}$, TERI REYNOLDS ${ }^{1,2}$, SAID ABOUD $^{1}$, STEPHEN OBARO ${ }^{3,4}$ and JULIE MAKANI ${ }^{1,5}$ \\ ${ }^{1}$ Muhimbili University of Health and Allied Sciences, P.O. Box 65,001, Dar-es-Salaam, Tanzania \\ ${ }^{2}$ University of San Francisco, California, San Francisco, United States \\ 3 University of Nebraska Medical Centre, Nebraska, United States \\ ${ }^{4}$ University of Abuja Teaching Hospital, Abuja, Nigeria \\ 5University of Oxford, Oxford, United Kingdom
}

\begin{abstract}
Background: Infection is an important cause of morbidity in children with sickle cell anaemia (SCA). However, little is currently known regarding the spectrum of adaptive immune derangement in SCA, especially of populations in Sub-Saharan Africa. In this study, we investigated the phenotype and activation status of T and B lymphocytes among children with SCA in Tanzania.

Methods: We compared 30 children with SCA aged 1-6 years in steady-state with 10 age-matched controls. We assessed white blood cell count, $T$ and $B$ lymphocyte phenotype and activation status using an automated haematology analyser and multiparameter Flow Cytometry.

Results: In children with SCA, the absolute lymphocyte, monocyte and granulocyte counts were all increased. There was also an increase in proportion of central/transitional memory $(42.4 \%$ vs. $33.3 \%, p=$ $0.0100)$, effector memory ( $7.8 \%$ vs. $5.4 \%, p=0.0086)$ and terminally differentiated $(2.3 \%$ vs. $1.3 \%, p=0.0355)$ CD4+ $T$ cells as well as effector memory CD8+ T cells $(21.3 \%$ vs. $11.5 \%, p=0.0060)$ in children with SCA. In contrast, there was no difference in naïve, classical memory, atypical memory and IgM memory B-cells between the two groups. The level of activation of both $\mathrm{T}$ and $\mathrm{B}$ cells were comparable between children with and without SCA. Furthermore, we observed a significant inverse correlation between frequency of the effector memory CD8+ T cells and haematocrit (Spearman rho $=-0.3859, p=0.0352$ ).

Conclusions: Children with SCA in Tanzania show an absolute increase in all leukocyte types, including lymphocytes, with skewing of both $\mathrm{CD}_{4}+$ and $\mathrm{CD} 8+\mathrm{T}$ cells towards the memory phenotypes. These findings provide insights on the development of adaptive immunity which may have implications on vaccine responsiveness, allo-immunisation, auto-immune diseases and transplant immunology in children with SCA.
\end{abstract}

Keywords: sickle cell anaemia, B-cell, T-cell, lymphocyte, phenotype, activation, Tanzania

\section{Introduction}

Children with Sickle Cell Anaemia (SCA), the homozygous form of Sickle Cell Disease (SCD), have an increased risk of infection (Ramakrishnan et al., 2010). Notably, the risk is high for infection with encapsulated bacteria such as Streptococcus pneumoniae (Gill et al., 1995; Ramakrishnan et al., 2010). A number of innate immune impairments have been described in SCA, including loss of opsonophagocytic activity, which is postulated to confer increased risk of infection with encapsulated bacteria (Brousse et al., 2014). Furthermore, individuals with SCA have increased risk for allo-immunisation, auto-immune diseases, bone marrow transplant rejection (lannone et al., 2003; Horan et al., 2005; Alkindi et al., 2012; Fasano et al., 2015) and altered vaccine reactivity (John et al., 1984; Ballester et al., 1985; Hord et al., 2002; Purohit et al., 2012; Disu et al., 2016) which has brought to surface adaptive immune aberrations in SCA. Limited studies done have indicated increased immune activation (Hibbert et al., 2005; Keikhaei et al., 2013; Nickel et al., 2015a; Nickel et al., 2015b; van Beers et al., 2015; Vingert et al., 2014, 2015), dominant T helper 2 (Th2) CD4+ $T$ cell response, regulatory $T$ cell ( $T_{\text {reg }}$ ) dysfunction and loss of immunoglobulin $M$ (IgM)-secreting CD27+lgM high ${ }^{\text {ggD }}{ }^{\text {low }} \lg M$ memory B cells in SCA (Sanhadji et al., 1988; Wang et al., 1988; Rautonen et al., 1992; Musa et al., 2010; Weller et al., 2004). More remains to be uncovered

\footnotetext{
*Correspondence E-mail: ebalandya@muhas.ac.tz; ebalandya@yahoo.com
} 
on the breadth of adaptive immune impairment in SCA, especially among children with SCA in Sub-Saharan Africa where the burden of the disease is highest (Piel et al., 2010). Thus, in order to fully harness the immune function in optimizing vaccine responsiveness and reduce alloimmunisation, auto-immune disease and transplant rejection risk, a thorough understanding of the adaptive immune function in SCA is warranted. In this study, we investigated T and B lymphocyte phenotypes among children with SCA aged 1-6 years in comparison with agematched controls in Tanzania.

\section{Materials and Methods}

\section{Study design and subjects}

This descriptive cross-sectional study was conducted at the Muhimbili National Hospital in Dar es Salaam, Tanzania. We enrolled 38 children with SCA from the Muhimbili Sickle Cell programme cohort between December, 2015 and July, 2016. All children were at steady-state, defined as 3 or more consecutive months free from noticeable illness (infection or painful crisis) or hospital admission. Furthermore, all children had not received immunisation or blood transfusion in the past 3 months' prior enrolment. We also enrolled 12 children without SCA (haemoglobin AA; $\mathrm{HbAA}$ ) as controls. All children were between 1 and 6 years of age. Following parental written informed consent, clinical data and $5 \mathrm{~mL}$ of venous blood $(4 \mathrm{~mL}$ in Ethylene-diamine-tetraacetic acid [EDTA] tube, $1 \mathrm{~mL}$ in plain tube) was collected from study participants for isolation of peripheral blood mononuclear cells (PBMC) and serum.

\section{Haematology, Haemoglobin Phenotyping and Isolation of PBMC and serum}

Some $150 \mu \mathrm{L}$ of anticoagulated blood in EDTA tube was used for quantification of white blood cells (WBC), red blood cells (RBC), reticulocytes and platelets using XT-200oi Automated Haematology Analyser (Sysmex Corporation, Kobe, Japan). Haemoglobin phenotype was determined using Cellulose Acetate Haemoglobin Electrophoresis (Helena Laboratories, Gateshead, UK). Confirmation of HbSS phenotype was done using High Performance Liquid Chromatography (Variant I, Biorad, Hercules, CA, USA) (Makani et al., 2011).

The remaining blood in EDTA tube was used for PBMC isolation. Briefly, blood was carefully placed on a $50 \mathrm{~mL}$ LeucoSep ${ }^{\mathrm{TM}}$ cell separation tube (Greiner Bio-One, Kremsmùnster, Austria) containing $15 \mathrm{~mL}$ of Ficoll Paque ${ }^{\mathrm{TM}}$ PLUS density separation medium (GE Healthcare, Little Chalfont, UK), followed by centrifugation at Relative Centrifugal Force (RCF) of 800 for 15 minutes (Hettich Rotanta 460, Tuttlingen, Germany). Mononuclear cells were collected on the buffy coat. Cells were washed twice using RPMI 1640 medium supplemented with Penicillin and Streptomycin (Thermo Fisher Scientific, Waltham, MA, USA). Assessment of viability and cell counting was performed using the $\mathrm{NC}-100$ NucleoCounter ${ }^{\circledR}$ (Chemometec, Allerod, Denmark). Up to 2 million cells were used fresh for each of $T$ and $B$ lymphocyte staining panels. The remaining cells were mixed with freezing media (10\% Foetal Bovine Serum [FBS] in Dimethly Sulfoxide [DMSO]) and were placed on Nunc CryoTube ${ }^{\circledR}$ vials (Thermo Fisher Scientific, Waltham, MA, USA) for storage at $-190^{\circ} \mathrm{C}$ in liquid nitrogen freezer. For serum isolation, $1 \mathrm{~mL}$ of blood in plain tube was centrifuged at 1000 RCF for 10 minutes. The harvested serum was collected in micro centrifuge tubes (Molecular BioProducts, San Diego, CA, USA) for storage in $-80^{\circ} \mathrm{C}$ freezer.

\section{Malaria and HIV Tests}

The CareStart ${ }^{\mathrm{TM}}$ Plasmodium falciparum histidine rich protein-2 (HRP-2) antigen-detecting Rapid Diagnostic Test (Access Bio Inc., Somerset, New Jersey, USA) was used for malaria diagnosis using whole blood samples. Presence of HIV-1/2 proteins and/or antibodies in sera of study participants was tested using enzyme-linked immunosorbent assay (ELISA) using the Murex HIV $\mathrm{Ag} / \mathrm{Ab}$ Combination test (Murex Biotech Ltd, Dartford, UK) with appropriate positive and 
negative controls. Positive test was confirmed using Enzygnost HIV Integral II kit (Siemens, Munich, Germany). Interpretation of positive test was as per manufacturers' specifications.

\section{Flow cytometry}

Freshly isolated PBMC were stained for 30 minutes in the dark with flurophore-labeled monoclonal antibody cocktails specific for $\mathrm{T}$ and $\mathrm{B}$ cells. Following staining, cells were washed using phosphate buffered saline containing $1 \% \mathrm{FBS}$ (340 RCF, $10 \mathrm{~min}$ ), fixed using $0.5 \mathrm{~mL}$ of $1 \mathrm{X}$ CellFIX (BD Biosciences, San Jose, CA, USA) and acquired on FACS Canto II (BD Biosciences, San Jose, CA, USA). The T cell panel comprised of monoclonal antibodies specific for $\mathrm{CD}_{3}$ (AmCyan), CD4 (APC-Cy7), CD8 (Pacific blue), CD45RA (FITC), CD27 (APC), CD38 (PE) and HLA-DR (PerCPCy5.5). Surface expression profiles of $C D 45 R A$ and $C D 27$ were used to identify Naïve (CD45RA+CD27+), Central memory/Transitional memory (CM/TM; CD45RA-CD27+), Effector memory (EM; CD45RA-CD27-) and Terminally differentiated (TD; CD45RA+CD27-) CD4+ and CD8+ $T$ cell subsets. $T$ cell activation was assessed via surface expression of the activation markers CD38 and HLA-DR. The B cell panel comprised of CD19 (PerCP-Cy5.5), CD21 (PE-Cy7), CD27 (APC), $\operatorname{IgM}(\mathrm{PE})$ and IgD (FITC). Surface expression of CD27, IgM and IgD was used to identify Naïve (CD27-lgM+lgD+), Classical memory (CD27+lgM-lgD-), Atypical memory (CD27-lgM-lgD-) and IgM memory (CD27+lgM ${ }^{\text {high }}$ IgD ${ }^{\text {low }}$ ) CD19+ B cells (Ayieko et al., 2013). CD21-negative cells were identified as activated B cells. All antibodies were purchased from BD Biosciences (San Jose, CA, USA).

\section{Data analysis}

Flow Cytometry data was analysed using FlowJo (version 8.7.1). Statistical analysis was done using R (version 3.0.2) and GraphPad Prism (version 6) softwares. Non-parametric Mann Whitney $U$ test was used for two-group comparison of means. Fisher's Exact test was used for comparison of proportions. Spearman correlation was used for statistical association. Two-tailed P-values of $<0.05$ were considered statistically significant.

\section{Ethical considerations}

The study was approved by the Institutional Review Board of the Muhimbili University of Health and Allied Sciences.

\section{Results}

\section{HIV, malaria, cell yield and enrolment}

We initially enrolled 50 participants ( $38 \mathrm{HbSS}$ and $12 \mathrm{HbAA}$ ) into the study. All participants tested negative for malaria. One participant (HbSS) tested positive for HIV-1 and was not included in the analysis. The amount of blood collected from 9 participants ( $7 \mathrm{HbSS}[18 \%$ of all $\mathrm{HbSS}]$ and $2 \mathrm{HbAA}$ [17\% of all $\mathrm{HbAA}]$ ) was small, resulting in low cell yield upon mononuclear cell isolation. These were also not included in the analysis. Thus, a total of $30 \mathrm{HbSS}$ and $10 \mathrm{HbAA}$ participants were included in final analysis. The average number of $C D_{3}+T$ cell and $C D 19+B$ cell events analysed on Flow Cytometry was 220,000 and 87,000 , respectively.

\section{Clinical and laboratory parameters}

Participants averaged 2.7 years of age in both groups. There were no differences in weight, height, pulse rate, systolic blood pressure (BP) or platelet count between the HbSS and HbAA groups. Spleen was palpable in two children with SCA $(2 \mathrm{~cm}$ in a 2-year-old and $6 \mathrm{~cm}$ in a 4-yearold). The RBC count, haematocrit and haemoglobin levels were lower among children with SCA compared to HbAA controls. Reticulocyte count was elevated in children with SCA (Table 1). 
Table 1: Clinical and laboratory parameters of the study and control groups

\begin{tabular}{|c|c|c|c|}
\hline Variable & $\operatorname{HbSS}(n=30)$ & $\operatorname{HbAA}(n=10)$ & P-value \\
\hline Age, years, Mean (SD) & $2.7(1.4)$ & $2.7(2.0)$ & 0.6890 \\
\hline Weight, Kg, Mean (SD) & $13.5(2.6)$ & $13.0(3.5)$ & 0.9700 \\
\hline Height, cm, Mean (SD) & $94.4(8.4)$ & $85.3(31.1)$ & 0.6500 \\
\hline Purse rate, bpm, Mean (SD) & $106.4(21.2)$ & $103.5(22)$ & 0.3510 \\
\hline Systolic BP, mmHg, Mean (SD) & $97.1(12.9)$ & $101.0(20.6)$ & 0.6350 \\
\hline Diastolic BP, mmHg, Mean (SD) & $54.6(13.8)$ & $64.8(17.9)$ & 0.1050 \\
\hline Palpable spleen, $n / n(\%)$ & $2 / 30(6.7)$ & $0 / 10(0)$ & 1.000 \\
\hline Red blood cell count, $\mathrm{X}_{10^{6}} / \mu \mathrm{L}$, Mean (SD) & $2.9(0.6)$ & $4.2(0.7)$ & $<0.001$ \\
\hline Haemoglobin, g/dL, Mean (SD) & $7.17(1.0)$ & $9.2(1.1)$ & $<0.001$ \\
\hline Haematocrit, \%, Mean (SD) & $21.7(3.0)$ & $29.6(3.0)$ & $<0.001$ \\
\hline Reticulocyte count, $\mathrm{X} 10^{6} / \mu \mathrm{L}$, Mean (SD) & $0.3(0.1)$ & $0.0(0.0)$ & $<0.001$ \\
\hline Reticulocyte percentage, \%, Mean (SD) & $11.8(5.1)$ & $0.9(0.4)$ & $<0.001$ \\
\hline Platelet count, $\mathrm{X}_{10^{3}} / \mu \mathrm{L}$, Mean (SD) & $424.7(211.6)$ & $434.4(186.8)$ & 0.8420 \\
\hline
\end{tabular}

A
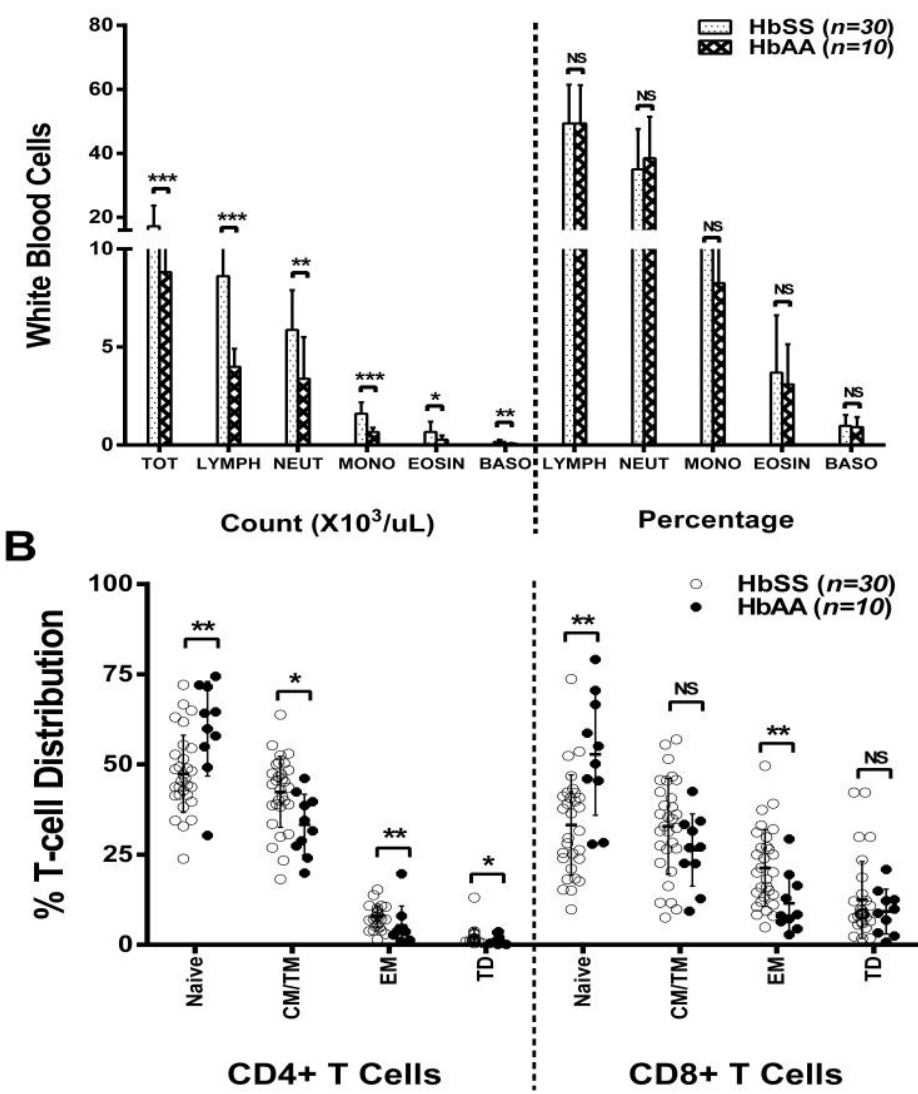

Figure 1: (A) White blood cells (WBC); (B) T cell phenotypes

Key: TOT $=$ Total, $\mathrm{LYMPH}=$ Lymphocytes, NEUT $=$ Neutrophils, MONO $=$ Monocytes, EOSIN $=$ Eosinophils, BASO $=$ Basophils. Error bars depict Standard Deviation (SD). NS = Not significant; * $P<0.05 ; * * P<0.01 ; * * * P<0.001$

\section{White blood cells}

In children with SCA, there was elevated total WBC count with an absolute increase in all types of white cells (lymphocytes, neutrophils, monocytes, eosinophils and basophils). However, the 
proportions of lymphocytes, neutrophils, monocytes, eosinophils and basophils were similar in children with SCA and in HbAA controls (Figure $1 \mathrm{~A}$ ).

\section{$T$ cell phenotypes and activation status}

The CD4:CD8 T cell ratio was comparable at 2:1 in both groups $(P=0.4485)$. With respect to subset analysis of $C D 4+T$ cells, in individual children with SCA, compared to HbAA controls, we found increased CM/TM, EM and TD CD4+ T cells, with concomitant reduction in the proportion of Naïve CD4+ T cells (Figure 1B). Similarly, we found elevated EM CD8+ T cell with reciprocal decrease in the proportion of Naïve CD8+ T cell in children with SCA compared to HbAA controls (Figure 1B). The level of activation of both CD4+ and CD8+ T cells, assessed via single and dual CD38 and HLADR expression, was comparable between the two groups (Figure 2).

\section{A}
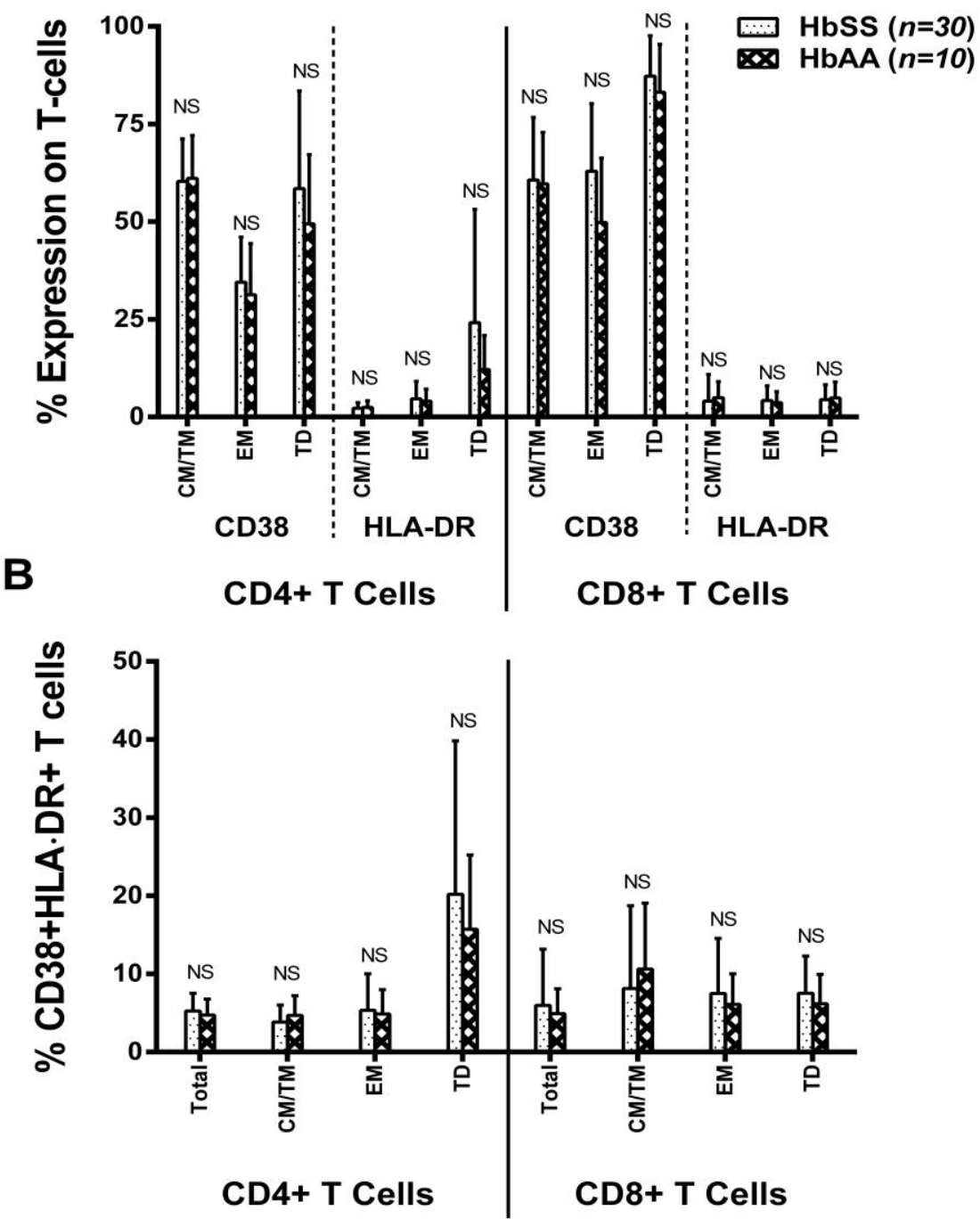

Figure 2: $T$ cell activation status $C D 4+$ and $C D 8+T$ cell activation was assessed via $(A)$ single expression of CD38 or HLA-DR, and (B) dual expression of both CD38 and HLA-DR on Total, CM/TM, EM and TD CD4+ and CD8+ T cells. Key: error bar depicts Standard Deviation; NS= Not significant

\section{B cell phenotypes and activation status}

The proportions of different CD19+ B cell subsets were comparable between the HbSS and HbAA groups (Figure $3 A$ ). Similarly, there was no difference in $B$ cell activation between the two groups as assessed via CD21 expression (Figure 3B). 


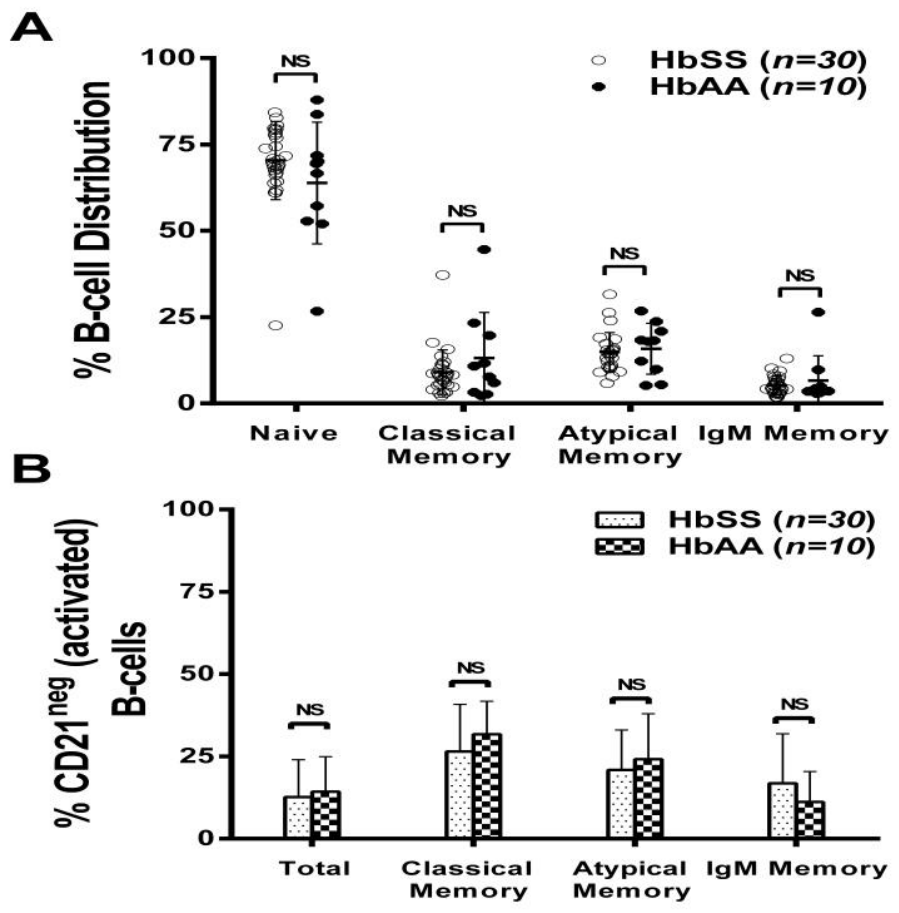

Figure 3: B cell phenotype and activation status: (A) percentage distribution of the naïve, classical memory, atypical memory and IgM memory CD19+ B cells were compared between HbSS and HbAA groups. (B) Activation status of the different $B$ cell subtypes were assessed via surface CD21 expression, and compared between HbSS and HbAA groups. Error bars depict Standard Deviation; NS = Not significant

A

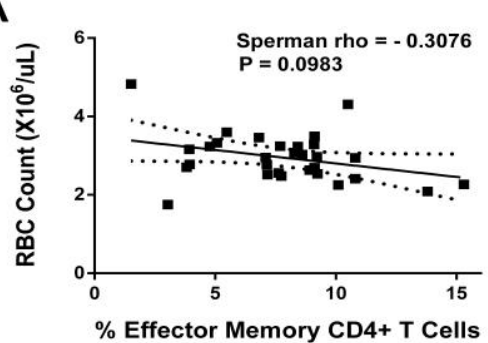

B

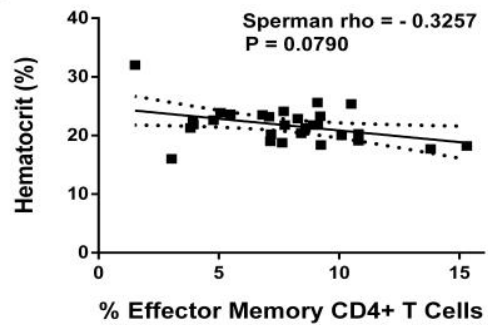

C

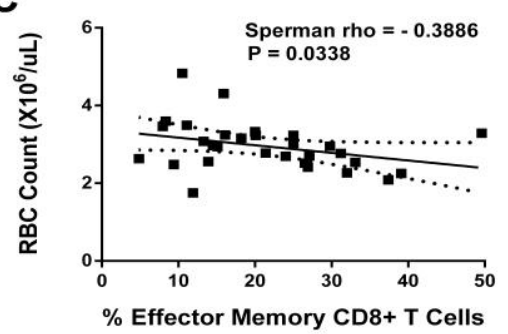

D

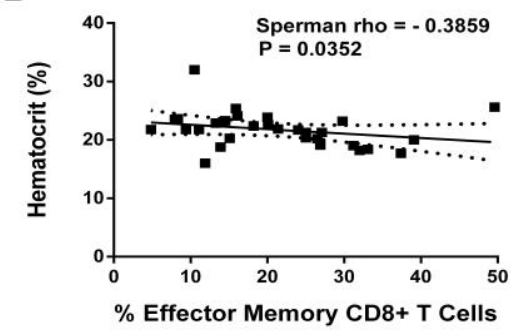

Figure 4: Correlation of EM T cell phenotype with RBC count and haematocrit. In A and B, RBC count and haematocrit correlated inversely with the proportion of EM CD4+ T cells. In $C$ and $D, R B C$ count and haematocrit correlated inversely with the proportion of EM CD8+ T cell.

\section{Association of T cell effector memory phenotype with RBC count and haematocrit}

We then sought to find association between the dominant EM phenotype of both $\mathrm{CD}_{4+}$ and CD8+ T cells with selected clinical and haematological parameters. In SCA, we found a significant negative correlation between the proportion of EM CD8 + T cells with RBC count and haematocrit 
(Figure $4 C$ and $D$ ). This correlation was also observed between EM CD4+ T cells with RBC count and haematocrit, although this did not reach statistical significance (Figure $4 \mathrm{~A}$ and $\mathrm{B}$ ).

\section{Discussion}

In the current study, we report that children with SCA at steady state had elevated WBC count, increased CM/TM, EM and TD CD4+ T cells as well as increased EM CD8+ T cells in peripheral blood. The distribution of $B$ cell subtypes as well as the level of $T$ and $B$ cell activation was comparable to those in children without SCA. Furthermore, we show that the increase in EM CD4+ and CD8+ T-cells in children with SCA negatively correlated with RBC count and haematocrit. These findings expand on our understanding of the development of adaptive immunity in children with SCA.

In the absence of interventions, many children with SCA succumb to bacterial infections early on in life (Thomas et al., 1982; Zarkowsky et al., 1986). Our study shows increased immune activity in children with SCA, even at steady state. The peripheral blood of children with SCA demonstrated a significant increase in cellularity of all WBC elements compared to children without SCA. Although the CD4:CD8 T cell ratio was preserved at 2:1, there was skewing of CD4+ T cells towards CM/TM, EM and TD phenotypes. Similarly, there was skewing towards EM CD8+ T cells, highlighting dominance of activity of the EM T cells in the SCA study population.

The cause for the observed alteration in lymphocyte phenotypes remains to be elucidated. With advancing age and progressive deterioration of splenic function, hyposplenism has been shown to contribute to lymphocyte abnormalities in SCA (Balandya et al., 2016). It is also possible that the observed increase in EM CD4+ and CD8+ T cells likely reflect immune activity against recent or possibly ongoing subclinical infection or vaso-occlusive events that may have been ignored in our study population at relative steady state (Sales et al., 2011; Keikhaei et al., 2013). The elevation of WBC count with propensity towards increased memory $T$ cells had been reported in a paediatric SCA population above 5 years of age in North America (Nickel et al., 2015b). Similar phenotypes have also been described among individuals with SCA who were alloimmunized (Nickel et al., 2015a).

Because of possible geographical differences in immune function (Lalor et al., 2011; Kollmann, 2013) and accentuated risk of infection in children with SCA below 6 years of age (Thomas et al., 1982), it was imperative to evaluate the immune phenotype in this at-risk age group, especially in Sub-Saharan Africa where the burden of SCA is highest (Piel et al., 2010). It remains to be determined whether these changes in T cell phenotype contribute to the observed alteration of vaccine reactivity in SCA (John et al., 1984; Ballester et al., 1985; Hord et al., 2002; Purohit et al., 2012; Disu et al., 2016). Further insight is thus needed regarding functional response of the different $T$ cell subsets to vaccines in children with SCA, including their ability to proliferate and secrete cytokines under antigenic stimulation. Similarly, studies are needed to elucidate $T$ helper 1 (Th1), Th2, Th17, follicular helper $\left(T_{f h}\right)$ and regulatory $C D 4+T$ cell $\left(T_{\text {reg }}\right)$ response to vaccines among children with SCA.

We did not observe overtly increased T cell activation via CD38 and HLA-DR expression among children with SCA in this study. However, presence of elevated WBC count with increased EM T cells suggests heightened state of immune response in SCA. Increased immune activation has previously been reported in SCA (Hibbert et al., 2005; Keikhaei et al., 2013; Nickel et al., 2015a, b; van Beers et al., 2015; Vingert et al., 2014, 2015), being more common in the presence of acute events such as vaso-occlusive crises (Bourantas et al., 1998; Keikhaei et al., 2013). The absence of overt immune activation in our study may thus be attributed to relative steady-state nature of our study participants. Presence of infection or vaso-occlusive crisis at the time of blood transfusion has been shown to influence the risk for allo-immunisation (Fasano et al., 2015). Since children with SCA may be transfused or vaccinated while having an infection or vaso-occlusive crisis, it is imperative to expand evaluation of immune activation and its impact on allo- 
immunisation and vaccine responsiveness among children with SCA in the presence and absence of these acute events. It will also be of interest to evaluate the impact of Hydroxycarbamide (hyroxyurea), which has been shown to reverse both the elevated WBC count and increased humoral mediators of inflammation in SCA (Lanaro et al., 2009; Nickel et al., 2015b). The use of hydroxyurea is currently been scaled up in Sub-Saharan Africa (McGann et al., 2016).

In contrast to $T$ cells, we did not observe differences in the distribution or activation status of the naïve, classical memory, atypical memory and IgM memory B cells between children with and without SCA in our cohort. The loss of IgM ${ }^{\text {high }}$ IgD low "IgM memory B cells" occurs in individuals with SCA following loss of splenic function (Brouss et al., 2014). These cells, which are normally resident in the marginal zone of the spleen (Weller et al., 2004), are usually lost as the splenic architecture is destroyed by repeated sickling (Booth et al., 2010; Brousse et al., 2014), leading to diminution of IgM response to immunization (Ballester et al., 1985). The preservation of IgM memory B cells in our study population likely indicates relative intactness of the splenic function in this younger patient population. It will therefore be of great interest to study longitudinal evolution of B cell phenotypes and function in SCA, including mitogen-induced proliferative response and immunoglobulin secretion, starting at a younger age.

To the best of our knowledge, this is the first study to show correlation of RBC count and haematocrit with frequency of EM T cells in individuals with SCA. We previously reported association of low haemoglobin with bacteraemia in individuals with SCA (Makani et al., 2015). The current findings thus corroborate our previous observation by hinting at increased adaptive immune surveillance in the setting of recent or ongoing subclinical infection as a possible explanation for elevated EM T cells in children with SCA having low haemoglobin (Sales et al., 2011). Whether anaemia precedes infection in this setting, or vice-versa, is yet to be elucidated. While infections are known to cause anaemia via induction of hepcidin and other mechanisms (Ganz, 2005; van Hensbroek et al., 2011), the suggestion that anaemia may predispose to infection has also been put forward, especially in the setting of increased haemolysis (Takem et al., 2014; Martins et al., 2016). The heme released during haemolysis is thought to favour increased susceptibility to non-thyroidal Salmonella (NTS), a common cause of bacteraemia (Makani et al., 2015), and other pathogens through increased iron availability (Takem et al., 2014) and impairment of phagocytic function (Martins et al., 2016). Thus, this scenario opens up the possibility that control of anaemia and haemolysis may lead to the reduction of infection and subsequently reversal of immune activation and normalization of the adaptive immune function in children with SCA. Indeed, the use of hydroxyurea, which increases foetal haemoglobin concentration (Lobo et al., 2013), has been associated with reduced haemolysis, reduced infections, reversal of immune activation and normalization of the frequency of memory $T$ cells in individuals with SCA (Goldberg et al., 1990; Lanaro et al., 2009; Lederman et al., 2014; Lobo et al., 2013; Nickel et al., 2015b). Thus, it is possible that improvement of foetal haemoglobin levels in children with SCA may lead to beneficial normalization of adaptive immune phenotypes and subsequently optimization of vaccine reactivity and reversal of allo-immunisation risk.

We acknowledge several limitations in this study. Firstly, by enrolling children with SCA free from noticeable infection, vaso-occlusive crisis or hospital admission in the past 3 months, we possibly selected for a subset of children with mild as opposed to severe form of SCA (Cetiner et al., 1989). Secondly, we did not objectively evaluate splenic function via quantification of Howell-Jolly bodies or ${ }^{99 m}$ Technetium scintigraphy of the spleen in this study (de Porto et al., 2010). Correlation of immune phenotypes with splenic function was therefore not possible. Lastly, the increase in erythropoiesis and consequently nucleated RBC, as evidenced by increased reticulocyte count, may have resulted in over-estimation of WBC count in children with SCA. However, elevated WBC count has been observed in other SCA populations previously (Nickel et al., 2015b).

In conclusion, we provide the first detailed analysis of adaptive immunity in children with SCA in Sub-Saharan Africa, showing increased memory T cell phenotypes and unaltered B cell 
subsets at steady state. The increase in EM T cells inversely correlated with RBC count and haematocrit, suggesting immune activity against recent or possibly ongoing subclinical infection in the presence of low haemoglobin in children with SCA. Future studies should investigate the functional status of the different $T$ and $B$ cell subsets in SCA as well as the impact of low haemoglobin, splenic dysfunction, immune activation, SCA severity and hydroxyurea on vaccine responsiveness and allo-immunisation in individuals with SCA. Findings from these studies may lead to newer approaches in optimizing vaccine responsiveness and combating alloimmunisation, auto-immune diseases and transplant rejection in children with SCA.

\section{Acknowledgements}

Special thanks to children who participated into the study and their families. Many thanks to Prof. Lucio Luzzatto (Visiting Professor of Haematology, Muhimbili University of Health and Allied Sciences), Dr. Furahini T. Chinenere, Dr. Raphael Sangeda, Mr. Zakaria Mtulo and the entire study team for assistance during study planning, data collection, analysis and review of the manuscript. This work was supported by the US National Institutes of Health Research Training Grant \# R25 TWo09343 funded by the Fogarty International Centre and the National Health, Lung and Blood Institute, as well as the University of California Global Health Institute.

\section{Author contributions}

EB conceived the study, performed the research, analysed the data and drafted the manuscript. TR, SA, SO and JM participated in research design, provided guidance during data collection and critically revised the manuscript. All authors read and approved the final manuscript.

\section{Competing interests}

The authors have no competing interests.

\section{References}

Alkindi, S., Al-Maini, M. \& Pathare, A. (2012) Clinical and laboratory characteristics of patients with sickle-cell and autoimmune/connective tissue diseases. Rheumatology International 32, 373-378.

Ayieko, C., Maue, A.C., Jura, W.G., Noland, G.S., Ayodo, G., Rochford, R. \& John, C. C. (2013) Changes in B Cell Populations and Merozoite Surface Protein-1-Specific Memory B Cell Responses after Prolonged Absence of Detectable P. falciparum Infection. PLoS One 8: e67230.

Balandya, E., Reynolds, T., Obaro, S. \& Makani, J. (2016) Alteration of lymphocyte phenotype and function in sickle cell anaemia: Implications for vaccine responses. American Journal of Hematology 91: 938-46.

Ballester, O. F., Abdallah, J.M. \& Prasad, A.S. (1985) Impaired IgM antibody responses to an influenza virus vaccine in adults with sickle cell anaemia. American Journal of Hematology, 20: 409-412.

Booth, C., Inusa, B. \& Obaro, S.K. (2010) Infection in sickle cell disease: a review. International Journal of Infectious Diseases 14: e2-e12.

Bourantas, K.L., Dalekos, G.N., Makis, A., Chaidos, A., Tsiara, S. \& Mavridis, A. (1998) Acute phase proteins and interleukins in steady state sickle cell disease. European Journal of Haematology 61: 49-54.

Brousse, V., Buffet, P. \& Rees, D. (2014) The spleen and sickle cell disease: the sick(led) spleen. British Journal of Haematology 166: 165-176. 
Cetiner, S., Akoglu, T.F., Kilinc, Y., Akoglu, E. \& Kumi, M. (1989) Immunological studies in sickle cell disease: comparison of homozygote mild and severe variants. Clinical Immunology and Immunopathology 53: 32-39.

de Porto, A.P., Lammers, A.J., Bennink, R.J., ten Berge, I.J., Speelman, P. \& Hoekstra, J.B. (2010) Assessment of splenic function. European Journal of Clinical Microbiology and Infectious Diseases 29: 1465-1473.

Disu, E.A., Akodu, S.O., Arinola, O.G., Diaku-Akinwumi, I.N., Adedokun, B., Olopade, C.O. \& Njokanma, O.F. (2016) Pneumococcal-specific IgG levels after 13-valent pneumococcal conjugate vaccination in Nigerian children with sickle cell disease. Paediatrics and International Child Health 1-4.

Fasano, R.M., Booth, G.S., Miles, M., Du, L., Koyama, T., Meier, E.R. \& Luban, N.L. (2015) Red blood cell alloimmunisation is influenced by recipient inflammatory state at time of transfusion in patients with sickle cell disease. British Journal of Haematology 168: 291-300.

Ganz, T. (2005) Hepcidin--a regulator of intestinal iron absorption and iron recycling by macrophages. Best Practice and Research Clinical Haematology 18: 171-182.

Gill, F.M., Sleeper, L.A., Weiner, S.J., Brown, A.K., Bellevue, R., Grover, R., Pegelow, C.H. \& Vichinsky, E. (1995) Clinical events in the first decade in a cohort of infants with sickle cell disease. Cooperative Study of Sickle Cell Disease. Blood 86: 776-783.

Goldberg, M.A., Brugnara, C., Dover, G.J., Schapira, L., Charache, S. \& Bunn, H.F. (1990) Treatment of sickle cell anaemia with hydroxyurea and erythropoietin. New England Journal of Medicine 323: 366-372.

Hibbert, J.M., Hsu, L.L., Bhathena, S.J., Irune, I., Sarfo, B., Creary, M.S., Gee, B.E., Mohamed, A.I., Buchanan, I.D., Al-Mahmoud, A. \& Stiles, J.K. (2005) Proinflammatory cytokines and the hypermetabolism of children with sickle cell disease. Experimental Biology and Medicine (Maywood) 230: 68-74.

Horan, J.T., Liesveld, J.L., Fenton, P., Blumberg, N. \& Walters, M.C. (2005) Hematopoietic stem cell transplantation for multiply transfused patients with sickle cell disease and thalassemia after low-dose total body irradiation, fludarabine, and rabbit anti-thymocyte globulin. Bone Marrow Transplantation 35: 171-177.

Hord, J., Windsor, B., Koehler, M., Blatt, J., Janosky, J. \& Mirro, J. (2002) Diminished antibody response to hepatitis $B$ immunisation in children with sickle cell disease. Journal of Pediatric Hematology/Oncology 24: 548-549.

Iannone, R., Casella, J.F., Fuchs, E.J., Chen, A.R., Jones, R J., Woolfrey, A., Amylon, M., Sullivan, K. M., Storb, R.F. \& Walters, M.C. (2003) Results of minimally toxic nonmyeloablative transplantation in patients with sickle cell anaemia and beta-thalassemia. Biology of Blood and Marrow Transplantation 9: 519-528.

John, A.B., Ramlal, A., Jackson, H., Maude, G.H., Sharma, A.W. \& Serjeant, G.R. (1984) Prevention of pneumococcal infection in children with homozygous sickle cell disease. British Medical Journal (Clinical Research Edition) 288: 1567-1570.

Keikhaei, B., Mohseni, A.R., Norouzirad, R., Alinejadi, M., Ghanbari, S., Shiravi, F. \& Solgi, G. (2013) Altered levels of pro-inflammatory cytokines in sickle cell disease patients during vasoocclusive crises and the steady state condition. European Cytokine Network 24: 45-52.

Kollmann, T.R. (2013) Variation between Populations in the Innate Immune Response to Vaccine Adjuvants. Frontiers in Immunology 4: 81.

Lalor, M.K., Floyd, S., Gorak-Stolinska, P., Ben-Smith, A., Weir, R.E., Smith, S.G., Newport, M.J., Blitz, R., Mvula, H., Branson, K., McGrath, N., Crampin, A.C., Fine, P.E. \& Dockrell, H.M. (2011) BCG vaccination induces different cytokine profiles following infant BCG vaccination in the UK and Malawi. Journal of Infectious Diseases 204: 1075-1085.

Lanaro, C., Franco-Penteado, C.F., Albuqueque, D.M., Saad, S.T., Conran, N. \& Costa, F.F. (2009) Altered levels of cytokines and inflammatory mediators in plasma and leukocytes of sickle 
cell anaemia patients and effects of hydroxyurea therapy. Journal of Leukocyte Biology 85: 235-242.

Lederman, H.M., Connolly, M.A., Kalpatthi, R., Ware, R.E., Wang, W.C., Luchtman-Jones, L., Waclawiw, M., Goldsmith, J.C., Swift, A. \& Casella, J.F. (2014) Immunologic effects of hydroxyurea in sickle cell anaemia. Pediatrics 134: 686-695.

Lobo, C.L., Pinto, J.F., Nascimento, E.M., Moura, P.G., Cardoso, G.P. \& Hankins, J.S. (2013) The effect of hydroxcarbamide therapy on survival of children with sickle cell disease. British Journal of Haematology 161: 852-860.

Makani, J., Cox, S.E., Soka, D., Komba, A.N., Oruo, J., Mwamtemi, H., Magesa, P., Rwezaula, S., Meda, E., Mgaya, J., Lowe, B., Muturi, D., Roberts, D.J., Williams, T.N., Pallangyo, K., Kitundu, J., Fegan, G., Kirkham, F.J., Marsh, K. \& Newton, C. R.(2011) Mortality in sickle cell anaemia in Africa: a prospective cohort study in Tanzania. PLoS One 6: e14699.

Makani, J., Mgaya, J., Balandya, E., Msami, K., Soka, D., Cox, S.E., Komba, A.N., Rwezaula, S., Meda, E., Muturi, D., Kitundu, J., Fegan, G., Kirkham, F.J., Newton, C.R., Snow, R.W. \& Lowe, B. (2015) Bacteraemia in sickle cell anaemia is associated with low haemoglobin: a report of 890 admissions to a tertiary hospital in Tanzania. British Journal of Haematology 171: $273-276$.

Martins, R., Maier, J., Gorki, A.D., Huber, K.V., Sharif, O., Starkl, P., Saluzzo, S., Quattrone, F., Gawish, R., Lakovits, K., Aichinger, M.C., Radic-Sarikas, B., Lardeau, C.H., Hladik, A., Korosec, A., Brown, M., Vaahtomeri, K., Duggan, M., Kerjaschki, D., Esterbauer, H., Colinge, J., Eisenbarth, S.C., Decker, T., Bennett, K.L., Kubicek, S., Sixt, M., Superti-Furga, G. \& Knapp, S. (2016) Heme drives haemolysis-induced susceptibility to infection via disruption of phagocyte functions. Nature Immunology 17: 1361-1372.

McGann, P.T., Tshilolo, L., Santos, B., Tomlinson, G.A., Stuber, S., Latham, T., Aygun, B., Obaro, S. K., Olupot-Olupot, P., Williams, T.N., Odame, I. \& Ware, R.E. (2016) Hydroxyurea therapy for children with sickle cell anaemia in Sub-Saharan Africa: rationale and design of the REACH trial. Pediatric Blood and Cancer 63: 98-104.

Musa, B.O., Onyemelukwe, G.C., Hambolu, J.O., Mamman, A.I. \& Isa, A.H. (2010) Pattern of serum cytokine expression and T-cell subsets in sickle cell disease patients in vaso-occlusive crisis. Clinical and Vaccine Immunology 17: 602-608.

Nickel, R.S., Horan, J.T., Fasano, R.M., Meyer, E., Josephson, C.D., Winkler, A.M., Yee, M.E., Kean, L.S. \& Hendrickson, J.E. (2015a) Immunophenotypic parameters and RBC alloimmunisation in children with sickle cell disease on chronic transfusion. American Journal of Hematology 90: 1135-1141.

Nickel, R.S., Osunkwo, I., Garrett, A., Robertson, J., Archer, D.R., Promislow, D.E., Horan, J.T., Hendrickson, J.E. \& Kean, L.S. (2015b) Immune parameter analysis of children with sickle cell disease on hydroxycarbamide or chronic transfusion therapy. British Journal of Haematology 169: 574-583.

Piel, F.B., Hay, S.I., Gupta, S., Weatherall, D.J. \& Williams, T.N. (2013) Global burden of sickle cell anaemia in children under five, 2010-2050: modelling based on demographics, excess mortality, and interventions. PLoS Medicine 10: e1001484.

Piel, F.B., Patil, A.P., Howes, R.E., Nyangiri, O.A., Gething, P.W., Williams, T.N., Weatherall, D.J. \& Hay, S.I. (2010) Global distribution of the sickle cell gene and geographical confirmation of the malaria hypothesis. Nature Communications 1: 104.

Purohit, S., Alvarez, O., O'Brien, R. \& Andreansky, S. (2012) Durable immune response to inactivated $\mathrm{H} 1 \mathrm{~N} 1$ vaccine is less likely in children with sickle cell anaemia receiving chronic transfusions. Pediatric Blood and Cancer 59: 1280-1283.

Ramakrishnan, M., Moisi, J.C., Klugman, K.P., Iglesias, J.M., Grant, L.R., Mpoudi-Etame, M. \& Levine, O.S. (2010) Increased risk of invasive bacterial infections in African people with sickle-cell disease: a systematic review and meta-analysis. Lancet Infectious Diseases 10: 329-337. 
Rautonen, N., Martin, N.L., Rautonen, J., Rooks, Y., Mentzer, W.C. \& Wara, D.W. (1992) Low number of antibody producing cells in patients with sickle cell anaemia. Immunology Letters 34: 207-211.

Sales, M.C., de Queiroz, E.O. \& Paiva Ade, A. (2011) Association between anaemia and subclinical infection in children in Paraiba State, Brazil. Revista Brasileira de Hematologia $e$ Hemoterapia 33: 96-99.

Sanhadji, K., Chout, R., Gessain, A., Sasco, A. J., Yoyo, M., Mezard, F., de The, G. and Touraine, J. L. (1988) Cell-mediated immunity in patients with sickle cell anaemia. Thymus 12: 203-213.

Takem, E.N., Roca, A. \& Cunnington, A. (2014) The association between malaria and non-typhoid Salmonella bacteraemia in children in sub-Saharan Africa: a literature review. Malaria Journal 13: 400.

Thomas, A.N., Pattison, C. \& Serjeant, G.R. (1982) Causes of death in sickle-cell disease in Jamaica. British Medical Journal (Clinical Research Edition) 285: 633-635.

van Beers, E.J., Yang, Y., Raghavachari, N., Tian, X., Allen, D.T., Nichols, J.S., Mendelsohn, L., Nekhai, S., Gordeuk, V.R., Taylor, J.G. \& Kato, G.J. (2015) Iron, inflammation, and early death in adults with sickle cell disease. Circulation Research 116: 298-306.

van Hensbroek, M.B., Jonker, F. \& Bates, I. (2011) Severe acquired anaemia in Africa: new concepts. British Journal of Haematology 154: 690-695.

Vingert, B., Tamagne, M., Desmarets, M., Pakdaman, S., Elayeb, R., Habibi, A., Bernaudin, F., Galacteros, F., Bierling, P., Noizat-Pirenne, F. \& Cohen, J.L. (2014) Partial dysfunction of Treg activation in sickle cell disease. American Journal of Hematology 89: 261-266.

Vingert, B., Tamagne, M., Habibi, A., Pakdaman, S., Ripa, J., Elayeb, R., Galacteros, F., Bierling, P., Ansart-Pirenne, H., Bartolucci, P. and Noizat-Pirenne, F. (2015) Phenotypic differences of CD4(+) T cells in response to red blood cell immunisation in transfused sickle cell disease patients. European Journal of Immunology 45: 1868-1879.

Wang, W.C., Herrod, H.G., Valenski, W.R. \& Wyatt, R.J. (1988) Lymphocyte and complement abnormalities in splenectomized patients with hematologic disorders. American Journal of Hematology 28: 239-245.

Weller, S., Braun, M.C., Tan, B.K., Rosenwald, A., Cordier, C., Conley, M.E., Plebani, A., Kumararatne, D.S., Bonnet, D., Tournilhac, O., Tchernia, G., Steiniger, B., Staudt, L.M., Casanova, J.L., Reynaud, C.A. \& Weill, J.C. (2004) Human blood IgM "memory" B cells are circulating splenic marginal zone $B$ cells harboring a prediversified immunoglobulin repertoire. Blood 104: 3647-3654.

Zarkowsky, H.S., Gallagher, D., Gill, F.M., Wang, W.C., Falletta, J.M., Lande, W.M., Levy, P.S., Verter, J.I. \& Wethers, D. (1986) Bacteremia in sickle haemoglobinopathies. Journal of Pediatrics 109: 579-585. 